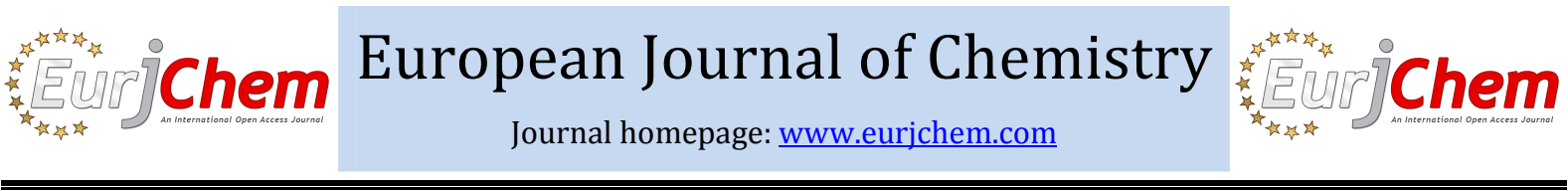

\section{Micellar high performance liquid chromatographic determination of tinidazole in combination with ciprofloxacin or norfloxacin in bulk, pharmaceutical dosage forms and in spiked human plasma}

\author{
Mohamed Rizk, Safaa Shafik Toubar, Maha Mahmoud Abou El-Alamin * \\ and Marwa Mohamed Mahmoud Azab \\ Analytical Chemistry Department, Faculty of Pharmacy, Helwan University, 11795, Cairo, Egypt \\ *Corresponding author at: Analytical Chemistry Department, Faculty of Pharmacy, Helwan University, 11795, Cairo, Egypt. \\ Tel.: +2.02.25541601. Fax: +2.02.25541601. E-mail address: dr.maha.alamin@gmail.com (M.M.A. El-Alamin).
}

\section{ARTICLE INFORMATION}

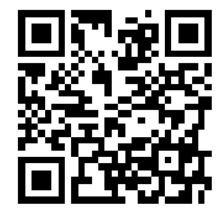

DOI: 10.5155/eurjchem.5.3.439-445.1037

Received: 26 February 2014

Received in revised form: 27 March 2014

Accepted: 27 March 2014

Online: 30 September 2014

\section{KEYWORDS}

\section{Stability}

Tinidazole

Method validation

Anti-protozoal drugs

Micellar liquid chromatography

Optimization and system suitability

\section{Introduction}

Tinidazole (TIN), is a 5-nitroimidazole compound with selective activity against anaerobic bacteria and protozoa. TIN has no activity against aerobic bacteria so, it must be combined with other antibacterial agents in the treatment of mixed infections involving aerobic and anaerobic bacteria. TIN has also been used successfully alone or in combination with other antimicrobial agents for prophylaxis in patients undergoing elective colonic and abdominal surgery, emergency appendectomy and gynecological surgery [1]. It is chemically described as 1-[2-(ethylsulphonyl) ethyl]-2-methyl-5-nitro- $1 H$ -imidazole [2] (M.W. = $247.3 \mathrm{~g}, \mathrm{p} K_{\mathrm{a}}=0$ ) (Figure 1). TIN bulk drug is official in British pharmacopeia [3], United State Pharmacopeia [4] and European Pharmacopeia [5].

Many methods for analysis of the cited compound have been reported, e.g. titrimetric method [3,5], spectrophotometric methods [6,7], flow injection analysis [8], spectrofluorimetric method $[9,10]$, electrochemical methods $[11,12]$ and chromatographic methods [13-16]. No micellar liquid chromategraphic method for simultaneous determination of TIN is available in the literature
Micellar liquid chromatography (MLC) is a form of reversed phase liquid chromatography that uses an aqueous micellar solution as the mobile phase. This technique is used mainly to enhance retention and selectivity of various solutes that would otherwise be inseparable or poorly resolved.<smiles>CCS(=O)(=O)CCn1c([N+](=O)[O-])cnc1C</smiles>

Figure 1. Structure of TIN, 1-(2-ethylsulfonylethyl)-2-methyl-5-nitroimidazole.

One of the most advantageous is the ability to directly inject physiological fluids. Micelles have an ability to solubilize proteins which enables MLC to be useful in analyzing untreated biological fluids such as plasma, serum, and urine. MLC is a better choice than ion-exchange LC or ion-pairing LC for separation of charged molecules and mixtures of charged and neutral species. Another novel application of MLC involves the 
separation and analysis of inorganic compounds, mostly simple ions. This is a relatively new area for MLC [17-19].

The aim of this work is to perform more accurate, reliable, fast and validated MLC method for determination of TIN alone or in combination with ciprofloxacin or norfloxacin in bulk, dosage form and spiked human plasma with a simple and rapid sample preparation especially for the routine analysis. Different chromatographic parameters were investigated to select the optimum conditions for the separation and applying as stability-indicating method for determination of TIN under different stress conditions. The result obtained by the proposed method was compared with that obtained by the HPLC technique [20]. The method was validated according to the international conference on harmonization guidelines (ICH) [21].

\section{Experimental}

\subsection{Materials}

TIN (99.5\%) was kindly supplied by Multiapex Pharma Drug Company (Badr City, Egypt). Ciprofloxacin (CIP) (99.8\%) was kindly supplied by Memphis Drug Company (Cairo, Egypt). Norfloxacin (NOR) (99.9\%) was kindly supplied by Memphis Drug Company (Cairo, Egypt). The pharmaceutical products used were Ciprogyl tablets (under trial) labelled to contain 600 $\mathrm{mg}$ TIN/tab, $500 \mathrm{mg}$ CIP /tab, were obtained from Research and Development Section in Memphis Company, Egypt. Conaz tablets (Batch 9160034) (Pharonia Pharmaceutical Company, Egypt) and Norfloxacin-TZ tablets (Batch 02321) (Sigma Pharmaceutical Company, Egypt) were purchased from the local pharmacy. They contain $600 \mathrm{mg}$ TIN and $400 \mathrm{mg}$ NOR/ tab. Plasma samples were obtained from Egyptian Research and Development Company and kept frozen until using after gentle thawing.

\subsection{Reagents and chemicals}

All Reagents were of analytical reagent grade and solvents were of HPLC grade. High purity water was obtained by Elga Labwater, Prima 7 (UK) and it was used throughout the study. Methanol, 1-propanol and acetonitrile (HPLC grade) were obtained from Sigma-Aldrich (Germany). Ortho-phosphoric acid (85\%), triethylamine (TEA) and sodium dodecyl sulphate (SDS, 99\%) were obtained from Riedel-deHäen (Sleeze, Germany). Sodium hydroxide and hydrochloric acid (32\%) were purchased from El-Nasr Company, Egypt. Hydrogen peroxide $(30 \%)$ was obtained from Luna industrial group (6 $6^{\text {th }}$ of October City, Egypt).

\subsection{Instrumentations}

The MLC method was performed on Agilent1200 HPLC auto sampler system equipped with UV detector 1200 (Germany) and HPLC quaternary pump 1200 (Germany). Analytical data is stored in a computer equipped with Agilent software. Vortex used was VWR VV3 S540 International (West Charter, USA). Centrifuge used was centurion, (West Sussex, UK). The $\mathrm{pH}$ was measured with Jenway pH meter, 3510, (Essex, UK). The mobile phase was filtered through Charles Austen pumps Ltd filter, model-B100 SE (England, UK). Ultrasonic bath used was Falc., (Treviglio, Italy). The mobile phase and the injected solutions were filtered through $0.45 \mu \mathrm{m}$ pore filters (Gelman, Germany).

\subsection{Chromatographic conditions}

MLC was performed on an intersil cyano column (5 $\mu \mathrm{m}$ particle size, $25 \mathrm{~cm} \times 150 \mathrm{~mm}$ i.d.), (GL Sciences Inc., Japan) using micellar mobile phase consisting of $0.1 \mathrm{M}$ SDS, $20 \% 1$ propanol, $0.3 \%$ TEA in $0.02 \mathrm{M}$ ortho-phosphoric acid: water
$(60: 40, v: v)(\mathrm{pH}=4)$. The mobile phase was filtered and sonicated for $30 \mathrm{~min}$ before use. The flow rate was $1.0 \mathrm{~mL} / \mathrm{min}$ and sample injection volumes were $20 \mu \mathrm{L}$ at room temperature $\left(25^{\circ} \mathrm{C}\right)$. The UV detector was operated at $311 \mathrm{~nm}$.

\subsection{Standard solutions}

Standard stock solutions of TIN / CIP combination (500 $\mu \mathrm{g}$ TIN and $416.7 \mu \mathrm{g} \mathrm{CIP} / \mathrm{mL}$ ) and TIN / NOR combination (500 $\mu \mathrm{g}$ TIN and $333.33 \mu \mathrm{g}$ NOR/mL were prepared by dissolving $50 \mathrm{mg}$ of TIN and $41.67 \mathrm{mg}$ CIP or $33.33 \mathrm{mg}$ NOR in $100 \mathrm{~mL}$ methanol then the solution was sonicated in an ultrasonic bath for 5 minutes. The solutions were found to be stable for 3 days at room temperature.

Working standard solutions (40-200 $\mu \mathrm{g} / \mathrm{mL})$ TIN combined with CIP or NOR were prepared by serial dilution of the standard solution with the mobile phase.

\subsection{Preparation of pharmaceutical products}

Take the contents of 20 tablets and determine the average weight of content per tablet. Accurate weight of the powder equivalent to $50 \mathrm{mg}$ ITC was dissolved in $100 \mathrm{~mL}$ methanol then sonication for $15 \mathrm{~min}$ and filtered.

\subsection{Plasma sample extraction}

$1 \mathrm{~mL}$ of human plasma was transferred into a centrifuge tube, spiked with $1 \mathrm{~mL}$ of TIN and deprotenized with $2 \mathrm{~mL}$ acetonitrile $(\mathrm{ACN})$, then vortex. Final concentrations were 80, 100 and $120 \mu \mathrm{g} \mathrm{TIN} / \mathrm{mL}$, respectively. The solutions were centrifuged at $5000 \mathrm{rpm}$ for 15 minutes. Then, the solutions were filtered through a disposable syringe filter $(0.45 \mu \mathrm{m})$ before column injection.

\subsection{Sample degradation}

An appropriate amount of TIN powder at a final concentration of $500 \mu \mathrm{g} / \mathrm{mL}$ in $1 \mathrm{~N}$ alcoholic $\mathrm{HCl}$ was left for 24 hrs then the solution was filtered and $2 \mathrm{~mL}$ was taken into 10 $\mathrm{mL}$ volumetric flask and the volume was completed with the mobile phase and triplicate $20 \mu \mathrm{L}$ injections were made. The same experiment was repeated but in $1 \mathrm{~N}$ alcoholic $\mathrm{NaOH}, 30 \%$ $\mathrm{H}_{2} \mathrm{O}_{2}$.

Each experiment was carried out in triplicate and all solutions were injected in triplicate. The nominal contents of each one were calculated using the constructed calibration graph or from the corresponding regression equation.

\section{Results and discussion}

The proposed MLC method represents a rapid and sensitive stability-indicating method for the separation and simultaneous determination of TIN in combination with either CIP or NOR in bulk and commercial tablets. Moreover, it was extended to investigate the inherent stability of TIN under different stress conditions. By virtue of its high sensitivity, the proposed method was applied for the determination of TIN in human plasma with no need for tedious sample pre-treatment steps.

Different parameters affecting the chromatographic performance of TIN were carefully studied in order to achieve the most suitable chromatographic system.

\subsection{Choice of appropriate detection wavelength}

The absorption spectrum of TIN in the mobile phase exhibits maximum absorption at $311 \mathrm{~nm}$ which allows also determination of CIP and NOR at this wavelength. So, $311 \mathrm{~nm}$ was selected as the optimum detection wavelength for detection and selective determination of TIN with a reasonable sensitivity in the presence of CIP or NOR. 
Table 1. Performance data of the proposed method for determination of TIN/CIP and TIN/NOR in pure form.

\begin{tabular}{lll} 
Parameter & Results & TIN/NOR \\
\cline { 2 - 3 } & TIN/CIP & $40-200$ \\
Concentration range $(\mu \mathrm{g} / \mathrm{mL})$ & $40-200$ & 4.07 \\
$\mathrm{LOD}(\mu \mathrm{g} / \mathrm{mL})$ & 5.6 & 12.34 \\
$\mathrm{LOQ}(\mu \mathrm{g} / \mathrm{mL})$ & 17.1 & 0.999 \\
$r$ & 0.999 & 1.2 \\
\%RSD & 1.9 & 0.25 \\
\% Error $(\% \mathrm{RSD} / \sqrt{\mathrm{n}})$ & 0.4 & \\
\hline
\end{tabular}
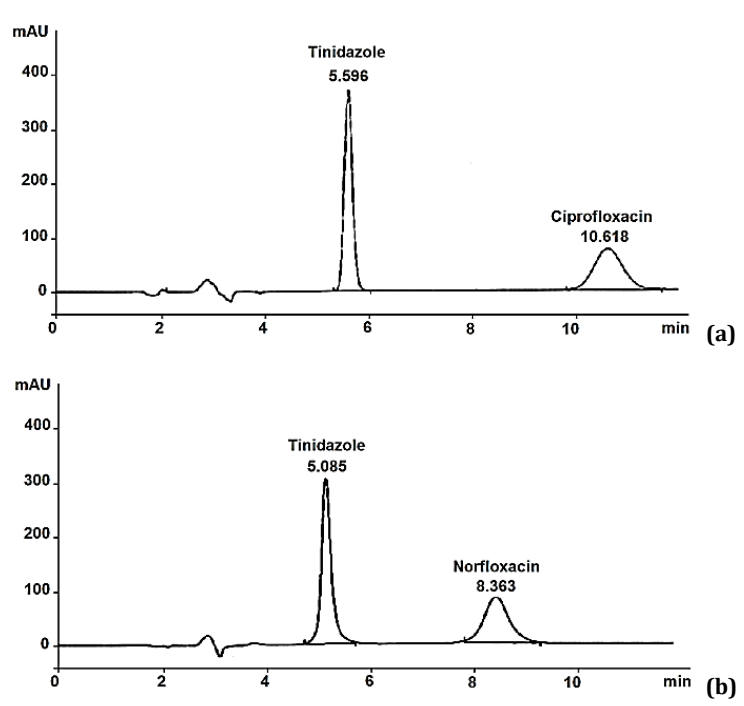

Figure 2. Representative chromatogram using the proposed method for simultaneous determination of TIN (100 $\mu \mathrm{g} / \mathrm{mL}$ ) in the presence of CIP (a), TIN (100 $\mu \mathrm{g} / \mathrm{mL}$ ) in the presence of NOR (b).

\subsection{Choice of column}

To investigate the chromatographic performance, different columns had been tried, these include reversed-phase C8, reversed-phase C18, two bonded phase cyano and bonded phase phenyl columns. Experimental trials revealed that the Intersil cyano column $(5 \mu \mathrm{m}$ particle size, $25 \mathrm{~cm}$ length, 150 mm i.d, GL Sciences Inc., Japan) was the most suitable one giving narrower symmetric peaks and highest number of theoretical plates within a reasonable analysis time.

\subsection{Mobile phase composition}

To achieve the best chromatographic conditions, the mobile phase composition was optimized to provide sufficient selectivity and sensitivity in a short separation time. The studied variables included; the $\mathrm{pH}$ of the mobile phase, flow rate, concentration of SDS, organic modifier and TEA.

\subsection{1. $\mathrm{pH}$ of the mobile phase}

In order to select the optimum $\mathrm{pH}$ value for the analysis of TIN, the $\mathrm{pH}$ of the mobile phase was studied over the range of 2.5-4.5. Mobile phases with $\mathrm{pH}$ values ranged from 3.5-4.0 provided suitable peak symmetry and better peak shape. Increasing the $\mathrm{pH}$ of the mobile phase more than 4.0 caused increase in the retention time of TIN. Finally, $\mathrm{pH}=4.0$ was selected as the optimum $\mathrm{pH}$ value for the mobile phase in this study yielding highest number of theoretical plates with good peak shape and lowest peak tailing.

\subsubsection{Flow rate of the mobile phase}

The effect of flow rate of the mobile phase on the retention of TIN was investigated over the range of $1.0-2.0 \mathrm{~mL} / \mathrm{min}$. Flow rate of $1.0 \mathrm{~mL} / \mathrm{min}$ was chosen since it provides better peak shape and better resolution within a reasonable time. After optimization of these variables, best peak shape, lowest peak tailing was achieved with well-defined peaks and good sensitivity within a reasonable analytical run time. Figure 2 represents a chromatogram indicating the good retention of TIN under the optimum chromatographic conditions.

\subsection{Method validation}

The validity of the proposed method was assessed by studying the following parameters in accordance to ICH guideline [21]: linearity, range, LOD, LOQ, accuracy, precision, selectivity, sample solution stability, mobile phase stability, system suitability and robustness.

\subsubsection{Linearity and range}

Under the optimum chromatographic conditions, a linear relationship was established by plotting average peak areas against TIN concentrations $(\mu \mathrm{g} / \mathrm{mL})$ as shown in Figure 3. The calibration graphs were found to be rectilinear over the concentration ranges of $40-200(\mu \mathrm{g} / \mathrm{mL})$ TIN.

Statistical analysis of the data showed good correlation coefficients $(r)$ and relative standard deviation as mentioned in Table 1.

$$
\begin{aligned}
& y=39.39 x+134.4(r=0.999) \text { for TIN/CIP } \\
& y=41.24 x+3.599(r=0.999) \text { for TIN/NOR }
\end{aligned}
$$

Limit of detection (LOD) and limit of quantification (LOQ) for TIN were calculated according to ICH Q2 (R1) recommendation [21] and the results are shown in Table 1. 
Table 2. Application of the proposed MLC method for the determination of TIN in combination with CIP.

\begin{tabular}{|c|c|c|c|c|}
\hline \multirow[t]{2}{*}{ Parameter } & \multicolumn{3}{|l|}{ Proposed method } & \multirow{2}{*}{$\begin{array}{l}\text { Comparison method [20] } \\
\text { \% Found* }\end{array}$} \\
\hline & Conc. taken $(\mu \mathrm{g} / \mathrm{mL})$ & Conc. found $(\mu \mathrm{g} / \mathrm{mL})$ & \% Found * & \\
\hline & 40 & 39.20 & 98.0 & 99.2 \\
\hline & 60 & 61.4 & 102.3 & 101.5 \\
\hline & 80 & 80.7 & 100.9 & 102.1 \\
\hline & 100 & 98.0 & 98.0 & 98.5 \\
\hline & 120 & 122.5 & 102.1 & 103.8 \\
\hline & 200 & 199.9 & 100.0 & 101.3 \\
\hline $\mathrm{x} \pm \mathrm{SD}$ & $100.2 \pm 1.9$ & & & $101.1 \pm 1.9$ \\
\hline t & $0.8(1.8) * *$ & & & \\
\hline $\mathrm{F}$ & $1.0(5.1) * *$ & & & \\
\hline
\end{tabular}

** Values between parentheses are the tabulated $\mathrm{t}$ and $\mathrm{F}$ values at $p=0.05$ [22].

Table 3. Application of the proposed MLC method for the determination of TIN in combination with NOR.

\begin{tabular}{|c|c|c|c|c|}
\hline \multirow[t]{2}{*}{ Parameter } & \multicolumn{3}{|l|}{ Proposed method } & \multirow{2}{*}{$\begin{array}{l}\text { Comparison method [20] } \\
\text { \% Found }\end{array}$} \\
\hline & Conc. taken $(\mu \mathrm{g} / \mathrm{mL})$ & Conc. found $(\mu \mathrm{g} / \mathrm{mL})$ & \% Found * & \\
\hline & 40 & 40.7 & 101.8 & 100.5 \\
\hline & 60 & 60.8 & 101.3 & 100.9 \\
\hline & 80 & 79.7 & 99.6 & 101.2 \\
\hline & 100 & 100.3 & 100.3 & 99.4 \\
\hline & 120 & 118.3 & 98.6 & 97.9 \\
\hline & 140 & 142.2 & 101.6 & 100.5 \\
\hline & 200 & 200.2 & 100.1 & 99.2 \\
\hline$\overline{\mathrm{x} \pm \mathrm{SD}}$ & $100.5 \pm 1.2$ & & & $99.9 \pm 1.2$ \\
\hline t & $0.8(1.8) * *$ & & & \\
\hline $\mathrm{F}$ & $1.0(3.8)^{* *}$ & & & \\
\hline
\end{tabular}

* Each result is the average of three separate determinations.

** Values between parentheses are the tabulated $\mathrm{t}$ and $\mathrm{F}$ values at $p=0.05$ [22].
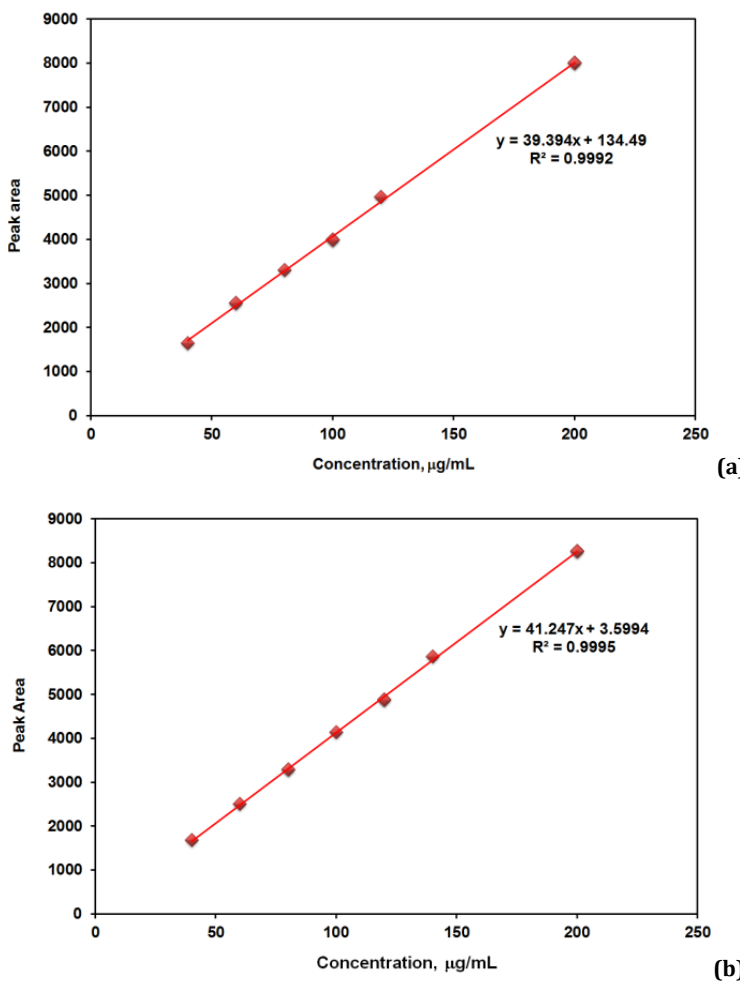

Figure 3. Calibration curve for simultaneous determination of TIN in pure form using the proposed MLC method in presence of (A) CIP in pure form, (B) NOR in pure form.

\subsubsection{Accuracy}

To prove the accuracy of the proposed method, the results of the assay of TIN in pure form by the proposed MLC method were compared with those obtained using a comparison HPLC method [20]. Statistical comparison of the results obtained by the proposed MLC method with those obtained by the comparison method using $t$-test and $F$-test revealed no significant differences between the performance of the two methods regarding the accuracy and precision, respectively. The results are shown in Table 2 and 3.

The comparison HPLC method involved the use of a mobile phase consisting of $0.05 \mathrm{M}$ SDS: $6 \%$ propan-1-ol $(47: 3, v: v)$ and $\mu$ bondapack cyano column at $320 \mathrm{~nm}$ [20]. 
Table 4. Precision data of the proposed method for the determination of TIN in dosage forms.

\begin{tabular}{lccc}
\hline & \% Found \pm SD & \%RSD & \%Error \\
\hline Intra-day precision & $108.0 \pm 1.0$ & 0.9 & 0.3 \\
Ciprogyl tab & $94.3 \pm 0.6$ & 0.6 & 0.2 \\
Conaz tab & $104.4 \pm 0.7$ & 0.7 & 0.2 \\
Norfloxacin-TZ tab & & 2.2 & \\
\hline Inter-day precision & $107.0 \pm 2.4$ & 2.3 & 0.5 \\
Ciprogyl tab & $95.7 \pm 2.2$ & 0.5 \\
Conaz tab & $102.2 \pm 2.6$ & 2.5 & 0.6 \\
Norfloxacin-TZ tab & & \\
\hline
\end{tabular}

Table 5. System suitability test parameters for the developed MLC method for TIN.

\begin{tabular}{lll}
\hline Parameter & TIN/CIP & TIN/NOR \\
\hline No of theoretical plates, N & 7145 & 4859 \\
Capacity Factor, K' & 0.84 & 0.84 \\
Selectivity factor, $\alpha$ & 1.95 & 1.92 \\
Resolution factor, $R_{\mathrm{s}}$ & 8.2 & 5.51 \\
\hline
\end{tabular}

Table 6. Application of the proposed and comparison method to determination of TIN in tablets.

\begin{tabular}{|c|c|c|}
\hline \multirow[t]{2}{*}{ Pharmaceutical preparation } & \multicolumn{2}{|c|}{$\%$ Found $*$, mean \pm SD } \\
\hline & Proposed & Reference [20] \\
\hline Ciprogyl tab & $105.8 \pm 1.6$ & $105.2 \pm 1.7$ \\
\hline$t^{* *}$ & 0.5 & - \\
\hline $\mathrm{F}^{* *}$ & 1.8 & - \\
\hline Conaz tab & $97.3 \pm 1.7$ & $97.8 \pm 1.7$ \\
\hline$t^{* *}$ & 0.6 & - \\
\hline $\mathrm{F}^{* *}$ & 1.1 & - \\
\hline Norfloxacin-TZ tab & $101.4 \pm 1.3$ & $101.3 \pm 1.5$ \\
\hline$t^{* *}$ & 0.4 & - \\
\hline $\mathrm{F}^{* *}$ & 2.1 & - \\
\hline
\end{tabular}

* Each result is the average of four separate determinations and each one repeated three times.

** The tabulated $t=1.9$ and $\mathrm{F}=9.3$ at $n=12$ and $p=0.05$ [22].

\subsubsection{Precision}

Intra-day precision of the proposed method was achieved by six replicate determinations of $100 \mu \mathrm{g} / \mathrm{mL}$ TIN in the three dosage forms on three successive times in the same day. Interday precision was performed as intra-day but on three successive days. Small values of \%error and \%RSD revealed the precision of the proposed method. The results are illustrated in Table 4.

\subsubsection{Selectivity}

The specificity of the proposed MLC method was established by its ability to determine TIN in commercial tablets without interference from other drugs or common tablet excipients. Neither the combined drugs nor the common tablet excipients show any interfering peaks at the retention times of the drug, which proved the homogeneity and purity of the peak. Furthermore, to evaluate the specificity of the method to determine TIN in human plasma, blank plasma was diluted with the micellar mobile phase and injected under the recommended chromatographic conditions. No endogenous interference was observed at the retention time of TIN, proving the specificity of the method.

Forced Degradation studies were also performed to evaluate the validity of the method. The results obtained indicated that the proposed MLC method is selective and able to determine TIN in presence of its degradation products.

\subsubsection{Sample solution stability and mobile phase stability}

Evaluation of the stability of TIN in its three dosage forms solution was achieved by quantification of TIN on three successive days and comparison to freshly prepared dosage forms solution. Similarly, the stability of the mobile phase was checked. No significant changes were observed, proved that the sample solution and mobile phase used during the assay were stable up to 3 days.

\subsubsection{System suitability test (SST)}

Evaluation of SST parameters was performed during the development and optimization of the method. The test was performed by injecting the standard sample in triplicate and the parameters were calculated as reported by USP [4]. SST parameters include capacity factor $\left(\mathrm{k}^{\prime}\right)$, selectivity factor $(\alpha)$, resolution factor $\left(\mathrm{R}_{s}\right)$, column efficiency (Number of theoretical plates, N). The final SST parameters under the optimum chromatographic conditions are illustrated in Table 5.

\subsubsection{Robustness}

To assess the robustness of the proposed MLC method, chromatographic conditions were deliberately altered. The tested variables included; concentration of 1-propanol $(20 \% \pm 0.5, v: v)$, strength of ortho-phosphoric acid $(0.02 \pm 0.005$ $\mathrm{M})$, concentration of TEA $(0.3 \pm 0.01 \%)$. The efficiency of the separation of TIN was not affected by all the varied chromatographic conditions indicating the reliability of the proposed method.

\subsection{Applications}

\subsubsection{Application of the proposed method to the determination of TIN in tablets}

The developed MLC method was applied successfully for the assay of TIN in commercial tablets either in combination with NOR or CIP. No interferences were encountered from common tablet excipients.

The results obtained by the developed MLC method were statistically compared with those of the comparison HPLC method [20] using $t$-test and F-test. In both tests, the calculated values did not exceed the theoretical values at the 95\% confidence level, which indicated that there were no significant differences between the developed and comparison methods regarding accuracy and precision, respectively. The results are shown in Table 6. 
Table 7. Assay results for the determination of TIN in spiked human plasma using the proposed method.

\begin{tabular}{llll}
\hline Parameter & Conc. added $(\boldsymbol{\mu g} / \mathbf{m L})$ & Conc. found $(\boldsymbol{\mu g} / \mathbf{m L})$ & \% Recovery \\
\hline Spiked plasma & 80 & 80.9 & 101.1 \\
& 100 & 105.2 & 105.2 \\
\hline Mean\% \pm SD & 120 & 121.1 & 103.9 \\
\%R.S.D & $103.4 \pm 2.1$ & & \\
\% Error & 2.0 & & \\
\hline
\end{tabular}

* Each result is the average of three separate determinations.
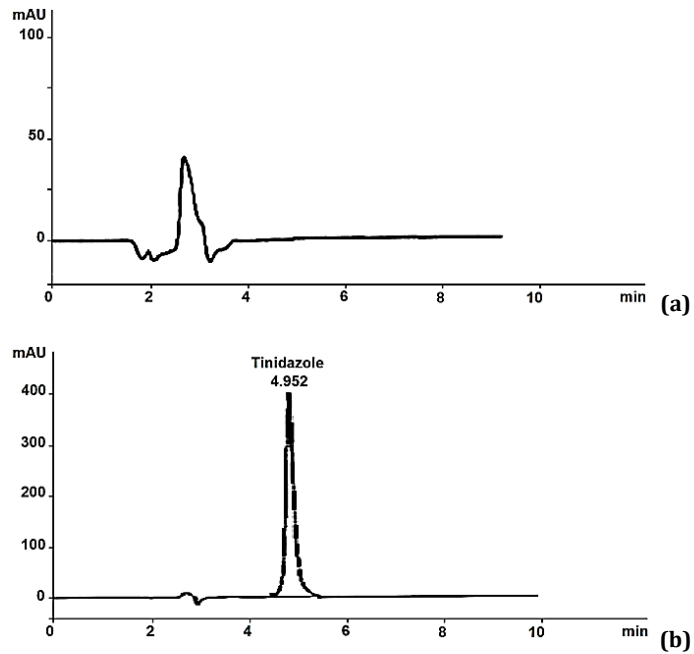

Figure 4. Representative chromatograms showing (a) Blank plasma and (b) plasma sample spiked with $120 \mu \mathrm{g} / \mathrm{mL}$ TIN.

\subsubsection{Application of the proposed method to the determination of TIN in spiked human plasma}

MLC allows biological samples to be analysed without prior tedious pre-treatment for plasma protein precipitation or elimination of other interfering substances, thus considerably reducing the cost and analysis time. The proposed MLC method was successfully applied to the determination of TIN in spiked human plasma.

The proposed method showed satisfactory results for determination of TIN in spiked human plasma. The assay results using the proposed method are summarized in Table 7. Figure 4 shows representative chromatograms for blank and spiked plasma samples.

\subsubsection{Results of stress testing studies}

The proposed method was applied to assess the inherent stability of TIN under different conditions like: alkaline, acidic, oxidative and photolytic conditions. The studied compound is found to be highly labile to alkaline hydrolysis, the solution upon addition of $\mathrm{NaOH}$, acquires a yellow colour [23]. Where the acidic degradation using $1 \mathrm{~N} \mathrm{HCl}$ for $24 \mathrm{hrs}$ resulted in about 2\%. Exposure of TIN to oxidative degradation by $30 \%$ $\mathrm{H}_{2} \mathrm{O}_{2}$ for $24 \mathrm{hrs}$, about $62.5 \%$ degradation of TIN was observed.

\section{Conclusions}

The proposed MLC method represents a new rapid and sensitive stability-indicating assay for the separation and simultaneous determination of TIN in bulk and pharmaceutical dosage form containing TIN/CIP or TIN/NOR. The proposed method was applied for the determination of TIN in human plasma with no need for tedious sample pre-treatment steps. In addition, the proposed method was extended to investigate the inherent stability of TIN under different stress conditions.

\section{Acknowledgements}

The authors thank Egyptian Research and Development Company for kindly effort providing during this work.

\section{References}

[1]. Palacin, C.; Tarrago, C.; Ortiz, J. A. Int. J. Gynecol. Obstet. 2000, 71, 37 46

[2]. Sweetman, S. Martindale, The Complete Drug Reference, $36^{\text {th }}$ edition, The Pharmaceutical Press, London, 2009.

[3]. The British Pharmacopeia, The stationary office, London, 2012 (Electronic version)

[4]. The United States Pharmacopeia $30^{\text {th }}$ edition and the National Formulary $25^{\text {th }}$ edition, Rockville, MD, USA, 2007, (Electronic version).

[5]. European Pharmacopeia Commission, $5^{\text {th }}$ edition, Supplement 5. 2 Council of Europe, Strasbourg, 2005.

[6]. Adegoke, O. A.; Umoh, O. E. J. Acta Pharm. 2009, 59, 407-419.

[7]. Mohammad, M. A.; Zawilla, N.; El-Anwar, F.; El-Moghazy, A. Chem Pharm. Bull. 2007, 55, 1-6.

[8]. Mohamed, M.; El-Gendy, A.; El-Bardicy, M.; Tawakkol, M.; Ahmad, A. J. Spectrosc. Lett. 1996, 29, 299-319.

[9]. Wang, J. Z.; Liu, B.; Sun, X. Q. Fenxi Ceshi Xuebao 2004, 23, 76-79.

[10]. Elokely, K. M.; Eldawy, M. A.; Elkersh, M. A.; El-Moselhy, T. F. Int. J. Anal. Chem. 2011, 2011, Article ID: 840178

[11]. Chenghang, W. E.; Fang, W.; Chunya, L. J. Pharm. Biomed. Anal. 2006 41, 1396-1400.

[12]. Merino, M.; Nunez-Vergara, L.; Squella. J. Electroanaly. 1999, 11, 12851292.

[13]. Bakshi, M.; Singh, S. J. Pharm. Biomed. Anal. 2004, 34, 11-18.

[14]. Argekar, A.; Powar, S. Indian Drugs 1999, 36, 399-402.

[15]. Tendolkar, N.; Desai, B.; Gaudh, J.; Shinde, V. Anal. Lett. 1995, 28, 1641-1653.

[16]. Argekar, A.; Kapadia, S.; Raj, S. Anal. Lett. 1996, 29, 1539-1549.

[17]. Armstrong, D.; Henry, S. J. Liq. Chromatogr. Relat. Technol. 1980, 3, 657-662.

[18]. Rizk, M.; Toubar, S. S.; El-Alamin, M. M. A.; Azab, M. M. M. Eur. J. Chem. 2014, 5(1), 11-17

[19]. Esteve-Romero, J.; Canda-Broch, S.; Gil-Agusti, M.; Capella-Peiro, M.; Bose, D. Trends. Anal. Chem. 2005, 24, 75-91.

[20]. Habel, D.; Guermouche, S.; Guermouche, M. J. Biomed. Chromatogr 1997, 11, 16-18. 
[21]. Validation of Analytical Procedure: Text and Methodology. International Conference on Harmonization Q2(R1), 2005 (http:// www.bioforum.org.il/Uploads/Editor/karen/q2_r1_step4.pdf).

[22]. Miller, J. C.; Miller, J. N. Statistics and Chemometrics for Analytical Chemistry, $5^{\text {th }}$ edition, Pearson Education Limited: Harlow, England, 2005, pp. 39-73, pp. 107-149, pp. 256.

[23]. Prasad, C. V.; Bharadwaj, V.; Parimoo, P. J. Pharm. Sci. 1996, 2, 255258. 